\title{
Standpoint Theory, in Science
}

A. Wylie and S. Sismondo

In: International Encyclopedia of the Social and Behavioral Sciences, second edition, edited by James D. Wright (area editor, Michael E. Lynch), Elsevier, 2015, pp. 324-330.

Standpoint theory is a social epistemology and aligned methodological stance predicated on the understanding that, as recent work in Science and Technology Studies (STS) has shown, scientific knowledge of all kinds is irreducibly social (e.g., see Science, Sociology of). It is characterized by a distinctive 'inversion' thesis according to which those who are marginalized or oppressed, and therefore often discounted as knowers, may in fact be better positioned to understand social relations and a range of other phenomena than those who are comparatively privileged. This thesis underpins research programs within the social and behavioral sciences and offers a rationale for participatory action and community-based collaborative research (PAR, CBPR) captured by critical race theorists, feminists and others who advocate 'starting research from the margins'. It has also been extended to the biological and physical sciences by practitioners and STS scholars who are intent on understanding how the social relations that structure scientific inquiry shape research agendas and outcomes across the sciences.

\section{Standpoint Theory's Central Argument}

The central arguments for attributing epistemic advantage to those who are oppressed or marginalized stem from Hegel's 'master-slave' dialectic, Marx's discussions of ideology, and particularly from Georg Lukaçs' discussion of the privileged standpoint of the proletariat. In his 1922 essay 'Reification and the Consciousness of the Proletariat' (in Lukacs 1971), Lukacs argues that the proletariat has the potential to develop a privileged standpoint from which to understand the rationalized structure of commodities and capital. Under capitalism the bourgeois tend to accept their position as natural and just because it was created by them; their class privilege makes it possible to retain a rationalizing illusion of subjectivity with respect to their own agency. By contrast, Lukacs argues, the social location of the proletariat is such that they routinely run up against arbitrary structures that oppress them and remove much of their subjectivity. In this they directly confront the constraining nature of the social relations that sustain capitalism, and the disconnect between these conditions of oppression and its rationalization. They thus have the resources to recognize that the system and its rationalization is an historical product, its contingency masked by the ideology by which it is legitimated. Louis Althusser and Antonio Gramsci also offer key insights for understanding how the lived experience of oppression can give rise to the formation of a critical standpoint on oppressive social arrangements (Hennessy 1993). In essence, then, these originating forms of standpoint theory offer an account of the blinding power of ideology, and of how it can be overcome (see Ideology, Sociology of).

Later standpoint theorists make that case that these insights can be extended to a range of intersectionally defined social locations. Social differentiation along lines of gender and race, for example, also has the potential to put those disadvantaged by systemic inequality in a position to understand its mode of operation and effects with particular clarity. As developed by feminist social scientists and theorists through the 1980s - for example, by Nancy Hartsock (1983), Patricia Hill Collins (1986), Dorothy Smith (1987), and Sandra Harding (1991) - the cornerstone of feminist standpoint theory is a recognition that the rationalization of gender norms as natural reifies social relations, and the observation that direct experience of gender discrimination had been the catalyst for articulating a distinctive perspective on gender relations. Crucially, feminist theorists argue that situated knowledge of this kind does not, in itself, constitute a standpoint (Hennessy 1993). It is through working against discrimination that it becomes possible to understand the contingency and the unfairness of ideologically rationalized conditions of life that go unrecognized or are unproblematic for those in positions of relative privilege. To the extent that these insights generate a critical standpoint on knowledge production - on the ways in which the institutions and products of science are inflected by systemic inequity and the ideologies that rationalize them - the situated knowledge of the dispossessed becomes relevant to doing and to understanding science. 


\section{Criticisms and Elaborations}

The central and most controversial claim associated with standpoint theory is that particular social positions have the potential to produce a privileged perspective, not merely another perspective. This has attracted two lines of critique: that, to sustain an attribution of epistemic privilege, standpoint theorists must be committed to an essentialist conception of the social location and identity of oppressed groups; and that they embrace an untenably strong formulation of the 'inversion' thesis according to which subordinate social location, in itself, warrants an automatic attribution of superior insight. Although the central tenets of standpoint theory have been developed in diverse ways by its advocates (see the Signs symposium on Hekman 1997), it is difficult to identify anyone who endorses either a strong essentialism or an automatic privilege thesis. These views are more typically attributed to standpoint theorists than embraced or presupposed by them, often in the context of the Science Wars and identity politics debates of the 1990s.

Where the charge of essentialism is concerned, standpoint theorists generally take as their point of departure well established critiques of naturalizing (e.g., bio-determinist) conceptions of gender and race difference that demonstrate the historical contingency of these social categories and of the systemic inequalities they underpin; rather than simply inverting the terms of these constructs, standpoint theorists understand them to function as ideological constructs in terms of which normative gender and race relations are reified and rationalized. In this spirit the assumption that women must all have something in common - some distinctive shared attribute, experience, or situation - has been steadily discredited by feminist researchers; intersectional analyses reveal a great deal of diversity among those who are structurally subordinate, where once was seen uniformity. By extension, the proliferation of feminist perspectives militates against any assumption that there is one correct feminist perspective from which vantage point the true nature of gender relations will be revealed. The methodological formulations of standpoint theory associated with Smith and developed by Harding - the recommendations to ask how the 'everyday world' looks to those who primarily operate 'off-stage' (Smith 1974) and to 'think from women's lives' (Harding 1991) - signals an early commitment to intersectional analysis and suggests how diversity can be built into standpoint theory.

The converse worry is that, if here is no gender-specific experience shared by all women, then there is nothing to ground a distinctive women's perspective or feminist standpoint. Similar concerns were raised in the context of the identity politics debates of the 1990s with respect to race and class identity, and a number of other subject positions that anchor standpoint theories. This objection only holds, however, if it can be demonstrated that social differentiation along lines of gender, for example, makes no difference to the experience of those so identified. Socialist feminists like Hartsock and Smith, who developed the framework for feminist standpoint theory in the 1970s and early 1980s, made the case for recognizing the ramifying impact of sex/gender norms on the lives of those socialized as women, shaping the material conditions of their lives, their relations of production and reproduction, and thus their epistemic capacities, their access to epistemic resources, and their credibility as knowers. More recently, feminist and critical race theorists (e.g., Alcoff 2006; Moya and Garcia 2000) have argued that collective identities do not have to be 'quasi-universal' to give rise to distinctive bodies of experience and perspective that can mobilize a critical standpoint on oppressive structures and the legitimating ideology of a dominant culture. This resonates with Rosemary Hennessy's recommendation that a feminist standpoint be understood as a form of 'critical practice'; its ground is not identification with an oppressed social group, but a 'disidentifying collective subject of critique', a subject position constituted through systemic analysis of the social production of difference (1993). The key point that emerges from this literature is that, although they are contingent historical constructs, systems of inequality structure our lives in ways that generate not just individual but systematic differences in what we are positioned to experience and to know, and in what resources we have for developing a critical standpoint on systemic inequality and its effects (Wylie 2012). Formulated in non-essentialist terms, this structural 'situated knowledge' thesis (Haraway 1991) is the central tenet of contemporary standpoint theory and the basis for its claims about epistemic advantage on the margins. 
The second line of criticism - that standpoint theorists accord automatic and comprehensive epistemic privilege to those who are socially marginal or subjugated - targets the 'inversion' thesis and reflects an anxiety about threats of relativism that is never far from the surface in debate about standpoint theory. The worry is that, in endorsing a 'situated knowledge' thesis, standpoint theorists undermine ideals of objectivity; if they hold that all knowledge is robustly contextual, they cannot but substitute an appeal to political values and interests for considerations of evidence and good reasons in the evaluation of knowledge claims. This line of argument presupposes a conventional understanding of objectivity by which it is equated with value-neutral, interest-free impartiality, and assumes that, if we give up the conviction that there are universal, trans-historical and context-transcendent norms of justification, then we have no basis for comparative evaluation of divergent knowledge claims; each is warranted locally, in its own terms and a debilitating epistemic relativism is inescapable. It is true that standpoint theorists join a broad constituency of science studies scholars and social epistemologists who have made a convincing case for various forms of contextualism (Knorr-Cetina 1981); they share an appreciation that appeals to context-transcendent norms of justification are not only untenable, but obscure the contingency and interest-specificity of the norms we have come to accept as a measure of objectivity.

At the same time, however, standpoint theorists argue that the polarized opposition between an idealized 'view from nowhere' and self-undermining relativism by no means exhausts the possibilities for adjudicating epistemic credibility (Rolin 2006). As critics and theorists of oppression, standpoint theorists clearly recognize that effective action aimed at changing oppressive social relations requires accurate, probative knowledge of these conditions and they are acutely aware of costs of being wrong. They are suspicious of illusions of certainty wherever they arise, but especially when these mask the interests embodied in dominant modes of understanding. Rather than rejecting objectivity as a regulative ideal, standpoint theorists are more typically intent on reformulating it in terms that take into account the situated nature of scientific inquiry and its extant norms of justification. The self-identified radical social constructionist Donna Haraway joins standpoint theorists in emphasizing the need to take up the challenge of developing a 'usable doctrine of objectivity', one that integrates both a recognition that all knowledges are situated and a 'non-nonsense commitment to faithful accounts of a "real" world' (1991, 86-88).

Standpoint theorists are notable for arguing that the resources of situated knowledge have the potential to significantly improve the reliability and integrity of the claims we ratify as knowledge; its partiality is not necessarily an epistemic liability. Harding, for example, advocates norms of 'strong objectivity' (1991, 1993), a requirement that the assessment of knowledge claims should take into account, not only the primary evidence and reasons presented in their support, but also the conditions under which they have been produced and ratified: the social, historical circumstances that have shaped the interests of practitioners, the institutional contexts in which they work, and the evolving norms of justification in terms of which these claims are warranted. The goal here is not wholesale rejection of authoritative sources of knowledge like the sciences but to calibrate our confidence in them and to determine how they might be improved, especially with respect to scope of applicability and broader impacts. In this spirit standpoint theorists direct attention to the transformative impact that feminist, race, class-based and other such critiques have had on a range of sciences. They note that, time and again, it has been outsiders to the research establishment or 'insider-outsiders' (Collins 1986) - practitioners who bring an underrepresented and sometimes an explicitly political angle of vision to bear - who have identified gaps and errors in research programs that privileged 'insiders' have persistently missed, raising the epistemic bar on a number of dimensions and opening up productive new lines of inquiry (Wylie 2003). Although she identifies as a constructive empiricist, Helen Longino's proceduralist account of objectivity captures a number of the insights that are central to the lessons standpoint theorists draw from consideration of such cases (Intemann 2010). She argues that the beliefs we should count as knowledge are those that have been subjected to critical scrutiny from 'multiple points of view' (2002); mobilizing the resources of diversely situated knowers can counteract the effects of insularity and contribute to the breadth and robustness of scientific thinking.

There is, however, no guarantee that the experience of oppression or marginality will, in itself, generate critical and constructive insights of these kinds. Standpoint theorists acknowledge that systems of oppression impose significant epistemic deficits on those they disadvantage; most obviously, the 
oppressed are often kept in their place in part by being denied access to key epistemic resources like literacy, education, and the information necessary to understand the systemic conditions responsible for their oppression (Narayan 1988), while insider-outsiders may be loath to risk their tenuous status by challenging community norms and can be fierce defenders of the status quo. Strong readings of the 'inversion' thesis are, then, clearly untenable: comprehensive epistemic 'privilege' cannot be attributed automatically to those who are oppressed just because they are oppressed and standpoint theory cannot provide a cut-and-dried formula for identifying particular standpoints that can be counted on to produce more objective knowledge. Not surprisingly, then, standpoint theorists typically construe the metaphor of privilege in terms of possibilities for understanding. As reformulated in response to critiques of essentialism and relativism, standpoint theory is best understood as a conceptual framework, an openended set of analytic resources, for addressing jointly descriptive and normative questions about the epistemic effects of oppression (Wylie 2012). Its point of departure is a situated knowledge thesis: one that presumes the epistemic relevance of systemic conditions of inequality without specifying in advance what their relevance will be in a given context. It directs attention to asymmetries in epistemic circumstance which suggest that important epistemic advantages (not privilege) may contingently accrue to those who are oppressed; in this it counters patterns of epistemic injustice by which the distinctive experience, perspectives, and hermeneutic resources of those who are socially marginal are discounted (Fricker 2007). And it provides a rationale for the normative thesis that scientific communities which are genuinely inclusive are more likely to recognize their own limitations and to produce a more balanced and better warranted understanding of their subject domain.

\section{The Domains of Standpoint Thinking in and About the Sciences}

There are a number of contexts in which standpoint theory, conceived in these terms, is relevant to the practice of science and to understanding the sciences. We identify two broad domains in which feminist and other genres of standpoint theory have been or can be productively applied.

\subsection{Content Critiques: From Problem Choice to Framework Assumptions}

Contextual values and interests - ideology of various kinds - most obviously affects the choice of topics that are given priority in the sciences. For example feminist critiques of sexism and androcentrism in the sciences, developed both by practitioners and science studies scholars, have been instrumental in bringing into sharp focus the gendered interests reflected in and served by the research agendas pursued by a predominantly male research establishment in a wide range of social, life and physical sciences. Standpoint theory figures both as a catalyst for these critiques and as a framework in terms of which to understand them.

Critiques of problem choice are best developed, and their standpoint theory implications most explicit, in the social sciences where social relations are a direct subject of inquiry. In any number of contexts researchers influenced by feminist, critical race, post-colonial theory and related perspectives have drawn attention to ways in which the research agenda in their fields takes the attributes, activities and interests of privileged men as the norm, focusing inquiry on questions that concern them. In the case of feminist research programs that took shape in the 1960s and 1970s, critiques of androcentrism catalyzed what were initially 'remedial' interventions aimed at adding women and gender to existing research programs. The women entering anthropology in unprecedented numbers in the 1960 s were quick to recognize the need for compensatory ethnography; the lack of attention to women as subjects meant that women's roles and relationships, distinctive sub-cultures and activities, were largely absent from ethnographic narratives. Early critics observed that this inattention reproduced characteristic 'dominant male systems of perception'; women's spheres and cultural understanding were considered only insofar as they figured in or were valued by the public languages and worlds of men (Ardener 1975). In a classic example from history, Joan Kelly-Gadol objected that the fortunes of women had been left out of account in research on the Renaissance (1977). Economists called into question estimates of national productivity that excluded consideration of the contributions made by women in the form of unpaid labor within the home or within family businesses (Waring 1988). The standpoint theorist Patricia Hill Collins $(1986,1993)$ drew on her working-class Black experience to throw into relief the race and class as well as gendered presuppositions that pervasively structured sociological research on 'the family'. And, famously, the feminist psychologist Carol Gilligan challenged Kohlberg's influential model of moral maturation on grounds that it had been based entirely on interviews with boys (1982). This commitment to redirect 
research priorities is also evident in a substantial shift of focus in primatology where projected gender norms had entrenched a presumption that 'primate society revolves around males' (Strum and Fedigan $2000,5)$; here a quite literal reorientation of field observation practice generated substantial new data on the roles and activities of female primates.

In all these contexts critiques of problem choice quickly exposed gender bias in framework assumptions and methodological norms that proved to have much wider implications, calling into question not just localized cases of science gone wrong, but pervasive androcentrism in science as usual, indeed, some of the best science on offer, as Harding described it (1986). The feminist anthropologists who turned their attention to the unstudied domestic spheres in which women operated soon recognized that the distinction between public and private was itself problematic; the problem with androcentric ethnographies was not just the absence of women but the imposition of ethnocentric categories presumed to be universal that did not begin to do justice to the diversity of gendered roles and relations they were encountering. The questions Kelly-Gadol raised about historical accounts of the Renaissance were intended from the start to challenge the periodization schemes in terms of which history has been written. The Renaissance, she argued, was anything but a period of cultural rebirth, viewed from the vantage point of women, moreover, the 'pattern of relative loss for women' that she noted for this period was a direct consequence of its accomplishments and typical for periods of 'so-called progressive change' (1976). Reflecting on women's history more generally, Peter Novick observes that 'feminist perspectives in history were as relevant to such male activities as war and diplomacy as they were to realms in which women dominated' $(1988,496)$. Likewise, historians, sociologists, and economists have all had to reassess the assumption that the 'household' could be taken for granted as a relatively fixed and uncontroversial unit of analysis. When they attended to gender roles and relations they found conflicts, differences in interest, and diverse social configurations that call into question not only what they had assumed about households, but about labor markets, 'human capital' and the causes and effects of poverty (Collins 1991). As controversial as Gilligan's positive account of a 'different voice' has been, her critique of Kohlberg was pivotal in destabilizing the Piagetian assumption that moral development must follow a single, universal trajectory. Finally, the new data from primatology has not only fundamentally changed our understanding of contemporary primates - bringing into focus the central role of females, and the importance of social dynamics other than aggression, hierarchy, and competition - it has also reframed theorizing about human evolution.

This roster of examples could be expanded in any number of directions. As Novick argues for history, critical analysis arising from underrepresented, subdominant subject positions - as defined by race, gender, and class, colonial status and indigeneity, by ablist and heterosexist norms, to name a few - have to varying degrees transformed virtually every field of human, social sciences since the 1970s, throwing into sharp relief the interest and context-specificity of entrenched, seemingly neutral field-defining agendas and framework assumptions. In this, standpoint theorists join science studies scholars in detailing myriad ways in which the values that set the research agenda also permeate the research process. Given their central interest in conditions of oppression, standpoint theorists are centrally concerned to understand, as well, the role played by authoritative research in the construction and legitimation of the social world from which these values arise. They attend to what lan Hacking refers to as 'looping' effects, by which scientists not only reproduce but participate in constituting and amplifying the social relations that they see in society (1999); they ask not only whose interests are reflected in entrenched research programs, but who benefits and who is harmed.

Such critiques are by no means limited to the social sciences. Consider, for example, the objections raised by the women's health movement of the 1960s and 1970s to the conventional focus of medical research on the ailments of men, and the presumption that male bodies and disease profiles could stand as the norm for the medical diagnosis and treatment of women. As Londa Schiebinger describes it, feminist activism was responsible for 'a great awakening... of mainstream medicine to women's health concerns'; it directed attention not only neglected conditions that are specific to women, like osteoporosis and breast cancer rather than heart disease and erectile dysfunction, but also put pressure on medical researchers to take account of ways in which women's health and disease profiles diverge from models based on studies of male subjects $(1999,113)$. Heart disease is one prominent example of a well studied condition the understanding of which was based, until the late 1980s, almost entirely on samples of men 
even though it concerned the effects of hormones like estrogen. More generally, the practice of relying on all-male samples to test drug safety and efficacy has been a highly visible target of critique, resulting in formal regulations that now require the inclusion of female subjects. The AIDS/HIV activism that resulted in the redesign of anti-retroviral drug trials is another well documented example in which outsiders to the research establishment played an instrumental role in exposing systematic bias in the direction of research effort (Epstein 1996). In the domain of technology (see Gender and Technology), both intended and indirect effects have been the focus of critique. In fact, every field of inquiry has at least some instrumental uses, and many forms of applied knowledge have some relevance to the gendered, as well as race and class structure of society. Topics within so-called 'pure' physics are connected to military uses, and are funded precisely because of those uses (see Science, Technology, and the Military). Those who have the least opportunity to participate in benefits of high status of military engagement suffer disproportionately from the consequences of war.

Contemporary standpoint theory was in large part catalyzed by these interventions. Harding was explicit that the motivation for her early exploration of standpoint theory was the question, 'why has the sex/gender system become visible only now?' (the title of Harding 1983). She found it striking that the incisive critiques of ingrained sexist and androcentric bias in status quo research programs had persisted for decades. On this and many other fronts the sciences had not proven to be self-correcting; the impetus to attend to longstanding gaps and distortions in scientific understanding of everything from social relations and sex difference to economic systems and biomedical conditions was due to external stakeholders whose interests were not reflected in or served by conventional research programs, and to the growing numbers of women and members of other underrepresented groups who entered the academy in the 1960s and 1970s. These critics drew explicitly on their distinctive situated experience in raising corrective evidence and insights that had not figured in their disciplinary tradition, but often their critiques were self-limiting; they did not intend to question entrenched norms of justification that privilege decontextualizing ideals of objectivity and many were vocal insisting that their contributions had nothing to do with their minority status. Those who did bring to bear feminist, critical race, queer, post-colonial, and other self-consciously situated, often explicitly political standpoints, did disrupt established patterns of thinking more fundamentally. But rather than compromising the integrity of the research process, the questions generated by their diverse perspectives often significantly raised the bar epistemically; they subjected entrenched assumptions to newly rigorous critical scrutiny and called for consideration of a wider range of interpretive or explanatory possibilities, new lines of evidence, and undervalued methodological strategies, in the process making substantial contributions to their disciplines' understanding of traditional as well as new subject matters.

This poses a challenge to conventional norms of justification and conceptions of objectivity on at least two fronts: it throws into relief the partiality and interest-specificity of bodies of knowledge that had been presumed objective (in the value-neutral, interest-free sense); and it demonstrates the epistemic contributions that can arise from mobilizing explicitly situated perspectives. Standpoint theorists take up this challenge, articulating the conceptual framework for a research program in social epistemology and STS (science and technology studies) that responds to this crisis of confidence in conventional norms of justification. It is characterized by the articulation of a situated knowledge thesis that highlights the systemic conditions that configure our epistemic capabilities, by an emphasis on recognizing epistemic advantage on the margins, and by the proposal of alternative conceptions of objectivity. This last includes proceduralist accounts that focus attention on the jointly social and cognitive conditions which ensure the possibility of transformative criticism, and norms of strong objectivity that build an ongoing critical appraisal of the conditions of knowledge production into the adjudication of knowledge claims.

\subsection{Equity Critiques and Collaborative Practice}

To varying degrees, diverse forms of discrimination are a normal part of the working environment in all of the sciences, embodied in everything from the allocation of funds and skewed citation patterns to patterns of workplace segregation, the structure of the tenure system, and the myriad effects of insider networks and hierarchical prestige systems. Equity activists, disproportionately women and members of other underrepresented groups, vocally challenge these entrenched practices as unjust and unsupportable in 
an enterprise defined by meritocratic ideals. Increasingly, however, the impetus for documenting and counteracting discrimination within the sciences is not only a commitment to social justice but, at an institutional and state level, by a concern that the sciences cannot afford to squander trained talent by tolerating sexist, racist and other prejudices. Standpoint theorists extend this generic argument for equity, arguing that discrimination exacts more specific costs than a diminution of the pool of trained talent; it robs the sciences of key epistemic resources as well. A growing number of cases bring to light the costs of gender-based discrimination: feminist examples include key discoveries by women that were not recognized for decades, and patterns of workplace segregation and citation bias that conspire to marginalize the contributions from subfields or in niches dominated by women. More generally, the recent history of content critiques outlined above draws attention to pervasive risks of group-think in socially homogenous, insular research communities. Standpoint theorists join equity activists in making the case for recruitment and training practices, and for reconfiguring reward structures, that will greater diversity in research communities, but they add a normative, epistemic justification for these interventions. They make the case that, although the contributions of researchers drawn from diverse backgrounds cannot be specified in advance, will expand the range of experience, heuristics, and perspectives that the scientific community can bring to bear in subjecting its norms of justification, and institutional practices as well as its best theories to critical scrutiny. There is ample evidence coming from a cross-section of the sciences - especially the social and behavioral sciences - that this kind of diversity is necessary to ensure the integrity and reliability of the knowledge ratified as scientific.

On this account standpoint theory is not only a critical practice but also a source of normative insight about strategies for improving scientific inquiry, making it more robust, relevant, and accountable. In this spirit Dorothy Smith has long insisted that standpoint theory is, above all, a methodology predicated on a commitment to level the hierarchical relationship between research and subject, recognizing the wisdom of insiders to the contexts studied by social scientists. This is the principle that underpins the recommendation to 'start research from the margins' (Smith 1974; Harding 1991). A similar case for recognizing relevant expertise held by non-scientists is also made in a range of biological, medical, and physical sciences. Brian Wynne details what sheep farmers know about the ecological impact of nuclear fall-out that scientists miss altogether in the context of an STS analysis of expertise (1996), and any number of citizen science initiatives, DIY-research communities, and the medical research activists discussed earlier bear witness to the expertise that lay practitioners have to offer fields as diverse as astronomy, genomics, infectious disease research, and field biology.

These principles of recognizing and engaging various forms of expertise that lie outside professional science are perhaps best exemplified by the long-standing traditions of community-based participatory research (CBPR) and participatory action research (PAR). The ideal here is that researchers should work in partnership with non-scientific communities, collaboratively defining the problems they will address and drawing on the expertise of community partners at every stage of the research program. The sociologists Elizabeth Petras and Douglas Porpora (1993) make the standpoint theory rationale for such practice explicit, arguing that PAR practice is motivated not only by a political, ethical commitment to be responsive to and to treat local communities respectfully, but by a recognition that the poor and oppressed bring significant epistemic resources to the table. They are 'epistemically privileged' in ways that can be expected to 'generate knowledge and insights' on a number of dimensions - a 'spectrum of theory, methods and substance" $(1993,107)$ - that represent significant contributions to disciplinary social science. The history of such research in its various forms is detailed with particular clarity in the context of recent debate about CBPR practice in development contexts (Hickey and Mohan 2004).

\section{Conclusions}

Science and technology studies bring into sharp focus the local and contextual origins of scientific knowledge; however universal the decontextualized results of inquiry may seem to be, they carry with them parochial assumptions that arise from a particular social order, and can play a powerful role in legitimating these assumptions. Standpoint theorists take up a particular set of questions and challenges posed by these insights. They engage in a practice of science critique aimed at countering the erasure of the situated interests that shape the sciences, and they are particularly attentive to the role played by dominant systems of knowledge in reproducing and amplifying systems of oppression. At the same time, 
standpoint theorists are intent on improving scientific practice. They draw a number of critical and constructive lessons from critiques which demonstrate that insular scientific communities are not reliably self-correcting; it often takes the input of 'insider-outsiders' who bring to bear dissonant experience and a critical angle of vision to identify persistent errors and missed possibilities in inquiry. Standpoint theorists make the case for a modest 'inversion thesis': that a range of epistemic advantages may accrue to those who must navigate the constraints of an oppressive social order from a position of systemic disadvantage. And they articulate, on this basis, an epistemic rationale for fostering diverse, representative, and democratic scientific communities: that the integrity and applicability of scientific knowledge requires the input of diverse critical perspectives, including those of nonscientists. This framework for critique and constructive intervention is potentially relevant to all branches of science, inasmuch as scientific inquiry is a thoroughly social process and perspectives that bring into view the effects of social structure are thus valuable throughout the sciences.

\section{Bibliography}

Alcoff LM 2006 Visible Identities: Race, Gender, and the Self. Oxford University Press, Oxford.

Ardener S 1975 (ed.) Perceiving Women. J. M. Dent \& Sons, London.

Collins P H 1986 Learning from the outsider within: The sociological significance of black feminist thought. Social Problems 33: 14-32

Epstein SG 1996 Impure Science: Aids, Activism, and the Politics of Knowledge. University of California Press, Berkeley CA

Fricker M 2007 Epistemic Injustice: Power and the Ethics of Knowing. Oxford University Press, Oxford.

Gilligan C 1982 In a Different Voice: Psychological Theory and Women's Development. Harvard University Press, Cambridge MA

Hacking I 1999 The Social Construction of What? Harvard University Press, Cambridge MA

Harding S 1983 Why has the sex/gender system become visible only now? In: Harding S, Hintikka M (eds.) Discovering Reality. Reidel, Dordrecht

---- 1986 The Science Question in Feminism. Cornell University Press, Ithaca NY

---- 1991 Whose Science? Whose Knowledge?: Thinking from Women's Lives. Cornell University Press, Ithaca, NY

---- 1993 Rethinking standpoint epistemology: What is 'strong objectivity'? In: Alcoff LM and Potter E (eds.) Feminist Epistemologies. Routledge, New York

Haraway D 1991 Situated Knowledges. In Haraway (ed.) Simians, Cyborgs, and Women: The Reinvention of Nature. Routledge, New York.

Hartsock N C M 1983 The feminist standpoint: Developing a ground for a specifically feminist historical materialism. In: Harding S, Hintikka M (eds.) Discovering Reality. Reidel, Dordrecht

Hekman S 1997 Truth and method: Feminist standpoint theory revisited Signs 22: 341-365

Hennessy R 1993 Women's lives/feminist knowledge: Feminist standpoint as ideology critique Hypatia 8: 14-34

Hickey S and Mohan G (eds.) 2004 Participation: From Tyranny to Transofrmation? Exploring New Approaches to Participation in Development. Zed Books, New York.

Intemann K 2010. 25 years of feminist empiricism and standpoint theory: Where are We Now? Hypatia 25: 778-796.

Kelly-Gadol J 1976 The social relation of the sexes: Methodological implications of women's history. Signs 1: 809-823.

---- 1977 Did women have a renaissance? In: Gridenthal R and Koonz C (eds) Becoming Visible: Women in European History. Houghton Mifflin, Boston

Knorr-Cetina K 1981 The Manufacture of Knowledge: An Essay on the Constructivist and Contextual Nature of Science. Pergamon, Oxford, UK

Longino H 2002 The Fate of Knowledge. Princeton University Press, Princeton NJ

Lukacs G 1971 History and Class Consciousness; Studies in Marxist Dialectics. MIT Press, Cambridge, MA

Moya PML, and Hames-García MR 2000 Reclaiming Identity: Realist Theory and the Predicament of Postmodernism. University of California Press, Berkeley CA

Narayan U 1988 Working together across difference Hypatia 32: 31-48. 
Novick P 1988 That Noble Dream: The 'Objectivity Question' and the American Historical Profession. Cambridge University Press, Cambridge.

Petras EM and Porpora DV 1993 Participatory research: Three models and an analysis. The American Sociologist 23: 107-26

Rolin K 2006 The bias paradox in feminist standpoint epistemology. Episteme 3: 125-136.

Schiebinger L 1999 Has Feminism Changed Science? Harvard University Press, Cambridge, MA

Smith D 1974 Women's perspective as a radical critique of sociology Sociological Inquiry 44: 7-13.

--- 1987 The Everyday World as Problematic: A Feminist Sociology. Northeastern University Press, Boston

Strum SC and Fedigan LM (eds.) 2000 Primate Encounters: Models of Science, Gender, and Society. University of Chicago Press, Chicago

Waring M 1988 If Women Counted: A New Feminist Economics. Harper \& Row, San Francisco

Wynne B 1996 May the sheep safely graze: A reflexive view of the expert-lay knowledge divide. In: Lash S, Szerszynski B, Wynne B (eds.) Risk, Environment and Modernity. Sage, London

Wylie A 2012 Feminist philosophy of science: Standpoint matters Proceedings and Addresses of the American Philosophical Association 86: 47-76

A. Wylie and S. Sismondo 